\title{
Institution of a Novel Curriculum Increases Scholarly Output Among Internal Medicine Residents
}

\author{
Mohammad Bilal $^{1,2} \cdot$ Yasmin G. Hernandez-Barco ${ }^{3} \cdot$ Sreeram Parupudi $^{2} \cdot$ Lindsay Sonstein $^{4} \cdot$ Karen Szauter $^{2}$. \\ Don W. Powell ${ }^{2}$
}

Published online: 8 January 2020

○) Springer Science+Business Media, LLC, part of Springer Nature 2020

\section{Introduction}

Despite the requirement of the Accreditation Council for Graduate Medical Education (ACGME) for residents to participate in scholarly activity during training [1], engaging in scholarly activities during residency can be challenging notwithstanding increasing concerns regarding the shortage of physician researchers in the USA [2, 3]. Scholarly activity and research are also essential for internal medicine residents applying for competitive specialty fellowship programs such as gastroenterology [4]. Therefore, we designed and implemented an individualized research curriculum in order to enhance gastroenterology-related scholarly output among medical residents.

\section{Methods}

The curriculum was created at the University of Texas Medical Branch at Galveston included: (1) learner assessment; (2) learner training; (3) establishing mentorship; and

Electronic supplementary material The online version of this article (https://doi.org/10.1007/s10620-020-06048-1) contains supplementary material, which is available to authorized users.

Mohammad Bilal

billa17@hotmail.com

Yasmin G. Hernandez-Barco

yhernandez-barco@mgh.harvard.edu

Sreeram Parupudi

srparupu@utmb.edu

Lindsay Sonstein

lksonste@utmb.edu

Karen Szauter

kszauter@utmb.edu

Don W. Powell

dpowell@utmb.edu
(4) dissemination of the work necessary for completion (Table 1). Our objectives were to: (1) foster and develop an interest in research and academic career paths; (2) meet ACGME requirements for required research activities during residency; and (3) increase knowledge regarding several types of scholarly activities including case reports or series, retrospective analyses, database studies, quality improvement projects, and formal meta-analyses.

\section{Learner Assessment}

Each interested learner underwent a thorough and detailed assessment of their background, interests, and skill sets by author MB, including evaluation of prior research experience such as laboratory research and prior advanced degrees. The goals of this assessment were twofold: identifying (1) the strengths and limitations of the learner and (2) the needs of learner. The strengths of the learner's skill set could include prior experience in writing case reports or other original works, statistical knowledge, familiarity with chart review for retrospective studies, or knowledge of using an administrative database. Identification of the learner's motivation to participate in scholarly work, e.g., evidence of a "thirst for knowledge" while a trainee, a demonstrated effort

1 Center for Advanced Endoscopy, Beth Israel Deaconess Medical Center, Harvard Medical School, 330 Brookline Avenue, Boston, MA 02115, USA

2 Division of Gastroenterology and Hepatology, The University of Texas Medical Branch, 301 University Blvd, Galveston, TX 77555, USA

3 Division of Gastroenterology, Massachusetts General Hospital, Harvard Medical School, 55 Fruit Street, Blake 4, Boston, MA 02114, USA

4 Department of Internal Medicine, The University of Texas Medical Branch, 301 University Blvd, Galveston, TX 77555, USA 
Table 1 Components of the curriculum

\begin{tabular}{|c|c|c|c|}
\hline Learner assessment & Learner training & Establishing mentorship & Dissemination of work \\
\hline $\begin{array}{l}\text { Evaluation of prior research } \\
\text { experience }\end{array}$ & IRB and CITI training & Pairing with sub-mentors & $\begin{array}{l}\text { Present preliminary data at local } \\
\text { meetings }\end{array}$ \\
\hline - Basic science research & $\begin{array}{l}\text { - First time participants, prepared } \\
\text { IRB submissions }\end{array}$ & - Junior faculty & $\begin{array}{l}\text { - Preparation for presentation at } \\
\text { national meetings }\end{array}$ \\
\hline - Prior $\mathrm{MPH}$ or $\mathrm{PhD}$ & & - Fellows & - Obtain feedback on research \\
\hline $\begin{array}{l}\text { - Previous scholarly work (written } \\
\text { case reports, review article, } \\
\text { chart review) }\end{array}$ & & - Residents for medical students & \\
\hline $\begin{array}{l}\text { Identifying strengths and limita- } \\
\text { tions the learner }\end{array}$ & $\begin{array}{l}\text { Training on using a manuscript } \\
\text { referencing software }\end{array}$ & Align goals of mentor-mentee & Training on manuscript submissions \\
\hline - Prior manuscript writing & - Endnote & - Area of interest & - Preparing cover letter, title page \\
\hline - Statistical knowledge/expertise & - Mendeley & - Timeline for publications & $\begin{array}{l}\text { - Writing response to reviewers' } \\
\text { comments }\end{array}$ \\
\hline \multicolumn{4}{|l|}{$\begin{array}{l}\text { - Efficient in chart review for } \\
\text { retrospective studies }\end{array}$} \\
\hline \multicolumn{4}{|l|}{$\begin{array}{l}\text { - Knowledge of using an adminis- } \\
\text { trative data base }\end{array}$} \\
\hline $\begin{array}{l}\text { - Limitations (e.g., maybe moti- } \\
\text { vated but no manuscript writing } \\
\text { experience) }\end{array}$ & $\begin{array}{l}\text { IHI modules for residents partici- } \\
\text { pating in quality improvement } \\
\text { projects }\end{array}$ & & \\
\hline Identification of learner needs & & Set a realistic timeline & $\begin{array}{l}\text { Identify suitable journals for manu- } \\
\text { scripts }\end{array}$ \\
\hline $\begin{array}{l}\text { - Wanting to learn or gain experi- } \\
\text { ence (intern or medical student) }\end{array}$ & & $\begin{array}{l}\text { - Timeline for abstracts in relation } \\
\text { to major conferences }\end{array}$ & \\
\hline $\begin{array}{l}\text { - Accumulate research experience } \\
\text { prior to fellowship applications } \\
\text { (second-year medical resident) }\end{array}$ & & $\begin{array}{l}\text { - Publications before applying for } \\
\text { fellowship }\end{array}$ & \\
\hline \multicolumn{4}{|l|}{$\begin{array}{l}\text { - Wanting to present at extramural } \\
\text { meetings }\end{array}$} \\
\hline \multicolumn{4}{|l|}{$\begin{array}{l}\text { - Personal growth (third-year } \\
\text { resident/fellow) }\end{array}$} \\
\hline & Manuscript writing training & $\begin{array}{l}\text { Establish the order of authorship } \\
\text { early }\end{array}$ & $\begin{array}{l}\text { Prepare learners for possible rejec- } \\
\text { tion and resubmission }\end{array}$ \\
\hline & $\begin{array}{l}\text { - Prior templates of similar } \\
\text { manuscripts }\end{array}$ & - Avoid confusion later & \\
\hline & $\begin{array}{l}\text { - Manuscript writing guidelines } \\
\text { (CONSORT, SQUIRE, CARE, } \\
\text { STROBE, etc.) }\end{array}$ & $\begin{array}{l}\text { - Build a relationship of trust and } \\
\text { transparency }\end{array}$ & \\
\hline & & $\begin{array}{l}\text { Sub-mentors to be readily acces- } \\
\text { sible }\end{array}$ & \\
\hline
\end{tabular}

to accumulate research experience for fellowship applications while a second-year resident, evidence of personal growth during third-year residency or fellowship, or a record of presentations at extramural scientific meetings comprised key baseline information. Based on this detailed assessment, scholarly work appropriate for the skill level of the learner was identified.

\section{Learner Training}

Training was undertaken including the taking the Collaborative Institutional Training Initiative (CITI) training modules in order to help learners understand the process of IRB submission guidelines based on the learner assessment and needs. Training was also provided with database software such as EndNote ${ }^{\mathrm{x} 9}$ and Mendeley. For learners participating in quality improvement projects, training was provided using the Institute for Healthcare Improvement (IHI) modules. Based on the type of project, learners were provided with examples of similar publications and with manuscript writing standards such as the CONSORT, CARE, and STROBE guidelines [5, 6]. 


\section{Establishing Mentorship}

The first two steps of the curriculum helped identify the mentor whose scholarly work goals best aligned with the strengths and needs of the learner. At the time of establishing mentorship, we set realistic timelines for each project, discussing and setting the order of authorship in order to teach effective time management and collaboration. Importantly, each learner was paired with a gastroenterology fellow or junior faculty, defined as "sub-mentorship." The goal of this was to pair the learner with someone who was readily accessible and closer to the learner in training, in order to foster comfort with reaching out with questions. Furthermore, learners were paired with a senior faculty member whose research and career interests aligned with that of the learner.

\section{Dissemination of Work}

The dissemination of work was prioritized keeping in view the strict timeline for learners. The learners were provided with all relevant major society abstract submission deadlines such as from the ACP, ACG, AGA, and AASLD. The learners were encouraged to present preliminary data at local and/or regional conferences. Special training was performed with regard to the manuscript submission process including writing cover letters, preparing the manuscript to adhere to a specific journal format, and responding to reviewers' comments by the sub-mentor in the form of group training and one-on-one revisions. For each submission, three journals were identified at the beginning of the submission process in order to prepare the learners for possible rejection and resubmission.

\section{Results}

The curriculum was applied to 16 internal medicine residents over a 30-month period between 2016 and 2019. Some learners participated in a single scholarly activity, while others produced multiple abstracts and manuscripts.

A total of 30 peer-reviewed publications whose authorship included the participating resident were published in journals indexed in PubMed. The residents were first authors on $90 \%$ of these publications ["please see Appendix of ESM"], significantly improved from 9 peer-reviewed gastroenterology-related publications published during the 3 years prior to the institution of the curriculum. Furthermore, 50 abstracts or presentations were submitted by participating learners to national meetings including to the ACG and ACP national meetings and to DDW. The list of publications involving the participating residents is provided in Appendix. A total of 7 national research awards including
Presidential Poster Abstract Awards, national ACP meeting presentation awards, and best poster presenter awards were attained by these learners in recognition of their scholarly work. Moreover, 9 research awards were won at local/ regional research meetings by the learners participating in the curriculum.

\section{Discussion}

Previous studies have shown that interventions including providing protected time and establishing research curricula or dedicated research pathways increase participation in scholarly activity [7], even though obtaining tangible products of scholarship such as presentations or publications was more difficult. Our curriculum was effective in producing a large number of publications and presentations in a short amount of time.

One of the major strengths and reasons for the success of our curriculum was the individualized approach. Whereas most residency research curricula are the same for everyone, our curriculum tailored resident/learner training to the unique needs of the learner. We also identified the most appropriate type of scholarly work for each learner based on their carefully and systematically assessed needs and strengths. The residents have very limited time to produce scholarly work during their training before fellowship applications are due, made all the more challenging when applying for fellowships in competitive specialties such as gastroenterology [4]. Each resident comes from a unique background; some are international medical graduates, though some have prior MPH or PhD degrees with its requisite training. Hence, since one size does not fit all, an individualized approach to engage them in scholarly activity keeping in mind their background is pivotal for their success in scholarly activity. Another element that we believe enhanced the success of our program was the introduction of "sub-mentorship." The senior mentors are often busy with their own research and administrative duties or increasing clinical pressures that decrease protected research time, any of which might impinge on their ability to mentor. Therefore, identifying appropriate sub-mentors for each project (e.g., pairing medical student with resident, or a resident with a fellow or junior faculty member) increased the efficiency of research projects, since the residents or students found it easier to communicate with sub-mentors in regard to arising issues related to the projects due to their accessibility.

In addition to the increased scholarly output, the development and institution of this curriculum has multiple other advantages. The curriculum facilitated professional development of the sub-mentors, since these fellows or junior faculty were able to gain the experience of mentoring residents through the many steps needed to envision, 
Fig. 1 Components of the individualized resident research curriculum

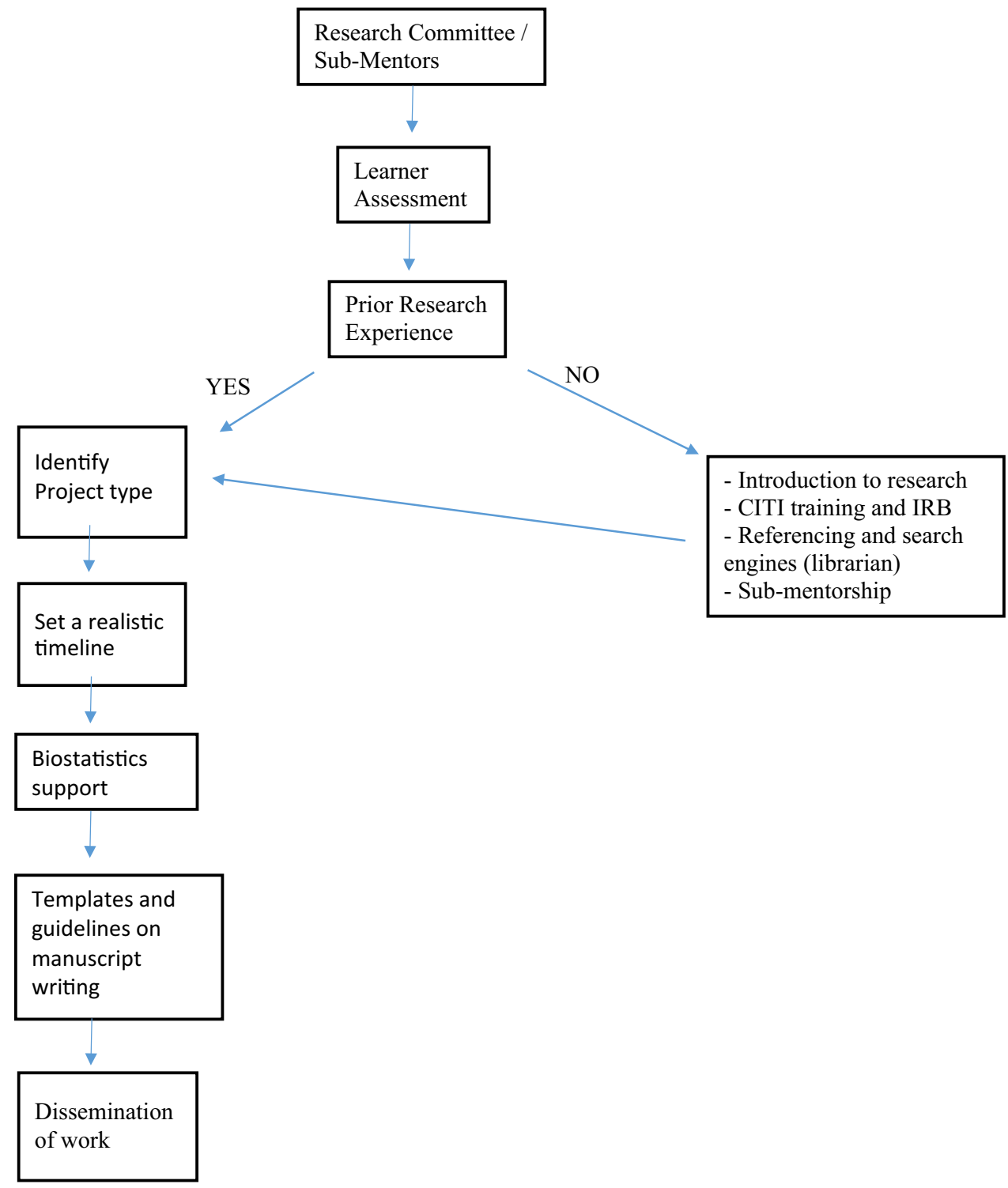

plan, fund, conduct, and disseminate clinical research, valuable skills for which many fellows or junior faculty often do not receive dedicated training. Curricula such as ours can prepare fellows to eventually become senior mentors as their careers progress. The curriculum structure also enabled multiple projects to continue simultaneously and hence increase the overall productivity of the institution. Moreover, this approach facilitates the conversion of multiple research hypotheses to abstracts or full-length publications, which can then serve as the basis for further research, hence advancing science.

Despite the success of our curriculum, its major limitation is that it has been implemented only at a single institution. Nevertheless, we believe that this model can be generalized (Fig. 1). The model is currently being implemented by author YGH at the Massachusetts General
Hospital in the form of the "Gastroenterology Research Collaborative" with encouraging preliminary results. The curriculum is also being disseminated through grand rounds presentations at other institutions.

In conclusion, a formal, systematic, and individualized curriculum improved gastroenterology-related scholarly output in internal medicine residents at our institution. Further outcomes from the implementation of this curriculum by other departments and institutions are needed to validate its generalizability and overall success.

Authors' contributions MB, SP, and DWP developed and applied the curriculum. YHB helped in refining the curriculum. LK and KZ helped in application of the curriculum. All authors contributed to the manuscript. 
Funding None with respect to this manuscript.

\section{Compliance with Ethical Standards}

Conflicts of interest The authors report no conflict of interest and have no financial disclosures with respect to this manuscript.

\section{References}

1. Accreditaton Council for Graduate Medical Education. ACGME common program requirements. Effective July 1, 2019. https ://www.acgme.org/Portals/0/PFAssets/ProgramRequirements/ CPRResidency2019.pdf. Accessed June 6, 2019.

2. Chesney RW, Dungy CI, Gillman MW, et al. Promoting education, mentorship, and support for pediatric research. Pediatrics. 2001;107:1447-1450.
3. Rosenberg LE. Young physician-scientists: internal Medicine's challenge. Ann Intern Med. 2000;133:831-832.

4. Atsawarungruangkit A. Association between proportion of US medical graduates and program characteristics in gastroenterology fellowships. Med Educ Online. 2017;22:1364604.

5. Gagnier JJ, Kienle G, Altman DG, et al. The CARE guidelines: consensus-based clinical case report guideline development. $J$ Clin Epidemiol. 2014;67:46-51.

6. Vandenbroucke JP. The making of STROBE. Epidemiology. 2007;18:797-799.

7. Stevenson MD, Smigielski EM, Naifeh MM, et al. Increasing scholarly activity productivity during residency: a systematic review. Acad Med. 2017;92:250-266.

Publisher's Note Springer Nature remains neutral with regard to jurisdictional claims in published maps and institutional affiliations. 